\section{Guidance on contraception for women aged over 40 years: response from the CEU}

I would like to thank Dr Al-Hassan for his comments ${ }^{1}$ on guidance about contraception for women aged over 40 years published in 2010. ${ }^{2}$ Many of the recommendations for contraceptive use in women aged over 40 years are based on the UK Medical Eligibility Criteria for Contraceptive Use published in $2010 .{ }^{3}$ Both of these evidence-based guidance documents ${ }^{23}$ therefore supersede any recommendation in guidance published prior to this. ${ }^{45}$ The FSRH Clinical Effectiveness Unit do not have the resource to update previous guidance in light of new recommendations. Readers are encouraged to be aware of any newer guidance that is published after any guidance document they use.

The UKMEC categories for depot medroxyprogesterone acetate (DMPA) use in women with hypertension are based on the UKMEC categories. ${ }^{3}$ There is no evidence that DMPA influences blood pressure. The use of DMPA is safe for women who are hypertensive. The categories in UKMEC are based on evidence and try to not restrict contraceptive methods to women with medical conditions where use is safe.

As you note Table $4^{2}$ considers the use of DMPA by women with hypertension that is adequately controlled (UKMEC 2: benefits outweigh the risks); consistently elevated $>140 \mathrm{~mm} \mathrm{Hg}$ systolic, $>90 \mathrm{~mm} \mathrm{Hg}$ diastolic (UKMEC 1: unrestricted use); or $\geq 160 \mathrm{~mm} \mathrm{Hg}$ systolic, $\geq 95$ diastolic $\mathrm{mm} \mathrm{Hg}$ or over (UKMEC 2: benefits outweigh the risks). The differences Dr Al-Hassan notes in the categories in Table $4^{2}$ take account of the use of antihypertensive medication, which is usually only commenced when there is a significant and sustained elevation in blood pressure. If a woman has normal blood pressure while using antihypertensive medications a UKMEC 2 category should simply flag up a medical condition that may itself may pose no problems but needs to be considered rather than no restriction being put on use.

I do not believe the evidence suggests that uncontrolled hypertension should be classified as UKMEC 3 (risks outweigh benefits) or UKMEC 4 (unacceptable health risk). This would unnecessarily restrict women from using a method of contraception that is longacting and effective.

\section{Susan Brechin, MRCOG, MFSRH}

Consultant in Sexual and Reproductive Health, NHS Grampian, Square 13 Centre for Sexual and Reproductive Health, Aberdeen Maternity Hospital, Aberdeen, UK; sue.brechin@nhs.net

\section{Competing interests None.}

J Fam Plann Reprod Health Care 2011;37:125. doi:10.1136/jprhc.2011.0085

\section{REFERENCES}

1 Al-Hassan N. Guidance on contraception for women aged over 40 years [Letter]. J Fam Plann Reprod Health Care 2011;37:124-125.

2 Faculty of Sexual and Reproductive Healthcare Clinical Effectiveness Unit. Contraception for Women Aged Over 40 Years. 2010. http://www.fsrh.org/admin/uploads/ Contraception0ver40July10.pdf [accessed 3 February 2011].

3 Faculty of Sexual and Reproductive Healthcare. UK Medical Eligibility Criteria for Contraceptive Use. 2010. http://www.fsrh.org/ admin/uploads/UKMEC2009.pdf [accessed 3 February 2011].

4 Faculty of Sexual and Reproductive Healthcare Clinical Effectiveness Unit. Progestogen-only Injectable Contraception. 2009. http://www.fsrh.org/admin/uploads/ CEUGuidanceProgestogenOnlylnjectables09.pdf [accessed 3 February 2011].

5 Faculty of Sexual and Reproductive Healthcare Clinical Effectiveness Unit. Progestogen-only Implants. http://www.fsrh.org/admin/uploads/ CEUGuidanceProgestogenOnlylmplantsApril08. pdf [accessed 3 February 2011]. 